IJßER

ISSN: 2149-5939
International Journal of Social Sciences and Education Research

Online, http://dergipark.gov.tr/ijsser

Volume: $4(4), 2018$

\title{
The lack of technology in teaching EFL to learners with dyslexia in Algeria
}

\author{
Miloud Fekih ${ }^{1}$
}

Submission date: 24 / $09 / 2018$

Accepted date: $08 / 11 / 2018$

\begin{abstract}
Technology has become a noteworthy element in teaching, including the case of EFL (English as a Foreign Language). There seems to be a never-ending list of various uses of technology to achieve and accomplish particular tasks in a spectrum of fields, such as business, medicine, architecture, and education. Teachers, in general, have to teach varied learners with different needs and exceptionalities, where technology is of paramount significance in order to help teachers accommodate the required interests of learners, especially for those with special educational needs such as dyslexia. The present paper aims to investigate Algerian EFL teachers 'perspective on dyslexia where teachers highlighted the lack of technology in teaching affected learners. A sample of 42 EFL teachers was recruited from different middle schools in Algeria from the four regions (North, West, East, and South). A triad of research tools was employed: a questionnaire, interviews, and ending up with focus group discussions. Results revealed that there is a serious reported lack regarding the use of technology in Algerian Middle schools. Additionally, Teachers reported that one of the biggest challenges that they face in Algeria is the classic way of teaching English where technology is still not used in a way that can make both processes of teaching and learning easy and effective. Likewise, findings showed that there is no particular technology in teaching those with dyslexia, where teachers highly recommend the integration of technology in Algerian schools for the purpose of improving the quality of education.
\end{abstract}

Keywords: Technology, Education, special needs, EFL teachers, Dyslexia, Algerian's classrooms

\section{Introduction}

According to Derntl and Calvo (2010), technology is very significant in education as it helps both teachers and learners. In the same way, Bain and Weston (2012) showed that the use of technology in teaching can have gains in both teachers' performance and learners' understanding. Hence, technology in education is a key element in successful teaching: in addition to providing learners with appropriate technological tools, it might also help in preparing teachers with technical skills and capacities they need to be successful in their classrooms where learners with special needs are of big concern.

Learners have diverse learning styles where technology can help teachers to accommodate those learning styles to deliver the lesson according to the way that works best for the learners especially those with learning difficulties. In fact, teachers need to be aware of the important use of technology as well as the different difficulties their learners encounter in the process of learning a language and how to make use from technology to meet everyone's needs. Thus, with more learners who have special needs in the general education classrooms, the need for appropriate

${ }^{1}$ University of the West of Scotland, UK 
Fekih, M. (2018). The lack of technology in teaching EFL to learners with dyslexia in Algeria. International Journal of Social Sciences and Education Research, 4(4), 721-729.

technology is fundamental to assist their learning by providing appropriate accommodation to their needs, and differentiated instruction.

Dyslexia is known also as reading disability, reading difficulty and or reading impairment. It takes a place when a person encounters serious difficulties in reading especially obstacles related with speed, accuracy, pronunciation and decoding even simple words, where also the understanding of the text and memorizing the vocabularies are also negatively affected. Dyslexia has nothing to do with intelligence: according to Fletcher et al. (1992), there are no differences in IQ between children who have dyslexia and those who have not. According to Lyon, et al (2003) Dyslexia

Is a specific learning disability that is neurobiological in origin. It is characterized by difficulties with accurate and/or fluent word recognition and by poor spelling and decoding abilities. These difficulties typically result from a deficit in the phonological component of language that is often unexpected in relation to other cognitive abilities and the provision of effective classroom instructions (p.2).

This can give a clear idea that the condition can harmfully affect many important language skills, and even worse than that, it may affect the psychological side and then make it more complicated for a learner to be academically successful. The definition also highlights a key component which is 'Classroom Instructions' where technology has a vital role.

It is also of paramount significance to know that those with dyslexia either being children or adults, man or women, they all have strengths points, aptitudes and skills which can be taken into consideration to compensate for the challenges in cognitive skills and improve their motivation in overcoming their difficulties.

\section{Literature review}

The history of dyslexia's understanding began just in the late 19th century. Reading difficulty was first developed and brought to light by a German physician Adolph Kussmaul who was interested in individuals with reading problems in the 1870s (Beaton, 2004). Kussmaul noted that those people with reading issues have normal intelligence where he thought that it is something to do with eyes and so he named it "word blindness" (Morgan 1886; Stengel, 1952). However, in 1887 the word dyslexia was for the first time coined by a German ophthalmologist named Rudolf Berlin (Anderson, and Meier-Hedde, 2001; Wagner 1973).

From the angle of helping those with dyslexia by developing techniques and methods to teach those with reading difficulties and helping them decreasing their troubles while learning, there are many ways especially with the use of technology. Orton (1925) created many teaching techniques and strategies during his research which are still in use today (Selikowitz, 2012). One of the Orton techniques is "Multisensory Methods" (Lerner and Johns 2014, p. 396). The main idea of this method is employ of all available senses at the same time when teaching those with dyslexia. This can be noticeably seen in Ott's expression which says "learners with dyslexia have to be taught through the use of the multi-sensory method to see, hear, say and type" (Ott, 2007, p. 232). Hence, affected learners can use their auditory and visual skills all together to learn. This method is named as Orton-Gillingham Approach to Dyslexia (Miles and Miles, 1999, p. 126-127) which has been utilized for many years and has been further refined by Hornsby (1975) and Hickey (1977). Refinement included: phonics, structured, cumulative, and sequential programs which incorporate multisensory techniques (Townend and Turner, 2012, p. 99). 
Fekih, M. (2018). The lack of technology in teaching EFL to learners with dyslexia in Algeria. International Journal of Social Sciences and Education Research, 4(4), 721-729.

In some cases, learners with dyslexia have difficulties with combining letters and pronouncing them correctly; these difficulties affect negatively the phonological skills of the learners and this is named as "Phonological Dyslexia" (Coltheart, 2005 p.16). In this case, and in order to help learners with phonological difficulties improve their capacities, techniques such as those designed by Nicolson et al (1999) and Hatcher (2003) can be effective.

In the same way, learners with reading impairment proved to have difficulties with fluency (Wolf, 2001). Vaughn et al. (2000) found that programs proposed to develop reading fluency and helping learners with dyslexia gaining the skills of memorizing and decoding the words easily. Moreover, Thompson and Vaughn (2004) suggested the use of tape-recorded readings, which can be book on $\mathrm{CD}$ that they can be accessed to computers. The computer can read aloud to the learner where vocabulary and important concepts can be reviewed and remembered correctly. Schneider and Crombie (2012) also emphasize the use of electronic-based technological materials in teaching a foreign language as technology helps them to learn as well as providing them with "the authentic EF and foreign language culture information far beyond that which the EL educator could provide on his/her own" (p. 76).

The use of computers has also been proved to be very significant in teaching learners with special needs such as those with dyslexia. Reid (2016) has highlighted the importance of using advanced technology in teaching both children and adults with dyslexia: according to Reid, computers can be particularly useful in overcoming the barriers of reading and writing as well. In the same way, Crombie (2015) cited in Reid (2016) points out how technology can help learners with dyslexia learn foreign languages. She recommended many computer activities text-to-speech software and other computers that can help those with dyslexia enhancing their level in reading and writing as well, in addition to giving them some independence in learning which is good for increasing their confidence and self-esteem.

According to Nagel (2013), although the advanced technology exists, in education there is still a lack of effective use of it. Nagel linked this lack of technology to many reasons such as poor funding, lack of preparation and lack of support. Schneider and Crombie (2012) have also highlighted that existing technology is not designed to meet the interests and needs of learners with specific language difficulties such as those with dyslexia. According to Schneider (1999) in every EFL classroom, we can find two to five learners with different degrees of language processing problems. In relation to this Schneider and Crombie (2012) claimed that there is a lack of appropriate technological materials that meet the need of those with dyslexia where we need to carefully choose what is beneficial for them.

According to Schneider and Crombie (2012), there are many countries that teach foreign language through the use of technology. However, Balckin and Wild (2018) found that teachers in Malaysia are struggling with the use of technology because of some reasons such as their limited capacities in mastering technology. Iknouye and Clarke (2017), also draw attention that teachers in Canada struggle somehow from the use of technology where teachers need more training where they identified that there is a lack of assessment criteria associated with the use of technology (p. 101). Wang (2014 ) stressed the importance of using technology in teaching in general where he brought to light the lack of teachers' skills in using technology according to the learners' interests and needs. Ertmer et al (2012) claimed that the student has to be taken into consideration when integrating technology in the classroom. 
Fekih, M. (2018). The lack of technology in teaching EFL to learners with dyslexia in Algeria. International Journal of Social Sciences and Education Research, 4(4), 721-729.

\section{Methods}

In order to know teachers' points of view regarding the use of technology in Algeria especially when teaching learners with dyslexia, three methods were implemented encompassing a webbased questionnaire which was considered as a starting research instrument to gather general information about the Algerian EFL teachers such as age, gender, experience and their place of work besides, their perspectives about learning disabilities particularly from an educational vision. Semi-structured interviews were employing as the focal research tool with the purpose of digging deeply into teachers point of views regarding the use of technology in teaching EFL in Algerian Middle school with a focus on teaching those with dyslexia. I ended up my data collection with the use of focus group were I gathered 8 EFL teachers to share their ideas and opening doors for them to suggest solutions and recommendation in order to improve the use of technology when teaching EFL to learners with reading difficulties. In this manner, my research methodology is made up of a mixed method of research tools where the quantitative instrument comes to be first conducted followed by the qualitative instruments. There are a lot of typologies of mixed approach methods designs that have been proposed by Creswell (2014) such as: multiphase design, embedded design, convergent parallel design, but in this research project I based my research on explanatory-sequential design as it follows my research plan in data collection which starts first which quantitative data collection and (questionnaire) followed by the collection of qualitative data (semi-structured interviews and focus group).

To explore EFL teachers' opinions and ideas regarding the situation of technology in teaching English in Algeria, I selected EFL teachers from different schools and district cities (rural, and urban areas), from all the four regions of Algeria (West, East, North, and South). A volunteer group of 42 teachers participated in the questionnaire. From the same group, 15 participants agreed to take part in the interviews that were conducted in different cities (according to the city where the participants teach and or live). From the same group, 8 teachers have again contributed to the focus group discussions. All participants involved completed informed consent forms, and were guaranteed confidentiality and anonymity.

Data analysis started with questionnaire followed by the recorded interviews that were analyzed altogether ending up with focus group discussion analysis and this is in respect to Creswell design (2014). Firstly, the questionnaire was analyzed quantitatively using the Statistical Package for the Social Sciences software (SPSS). Secondly, I analyzed interviews by transcribing and coding the answers according to categories and outline that matched with the use of technology. I identified specific themes that included (a) lack of technology in teaching (b) Reliance on traditional materials (c) lack of support to teachers.

\section{Findings}

The main objective of this study was recognizing the situation of technology and English language teaching in Algeria. In this section, I present explanations of the three main themes in addition to some participants' answers that support the actual goal of the study where all names are pseudo names.

\subsection{Questionnaire's findings}

The questionnaire as mentioned above was just a starting research tool to gather overall information about teachers and the situation of teaching learners with dyslexia in Algeria. In the 
Fekih, M. (2018). The lack of technology in teaching EFL to learners with dyslexia in Algeria. International Journal of Social Sciences and Education Research, 4(4), 721-729.

questionnaire, I left open space for teachers to speak about what they think regarding teaching learners with reading difficulties and what makes it complicated for them. Some participants expressed the struggle and or the difficulties that they both face as teachers and learners, and as part of this they raised the lack of awareness and lack of using technology in teaching and learning. For example, Participant number 16 stated that, "The lack of awareness and technology at schools can be one of the things that make reading difficulties unknown and complicated to be taught"

The quotation above can clearly illustrate teachers noticing the importance of technology and its potential role in facilitating both teaching and learning processes. Furthermore, through teachers' responses I tried to list what teachers reported in the survey as obstacles to the formal employ of technology. Firstly, the obstacle that teachers pinpointed out was the lack of training in using technology. The second obstacle that teachers reported was lack of familiarity with the sophisticated technology and maybe resistance to adopting modern ways of teaching. The third problem that teachers reported is their limited capacities in using technology especially to learners with particular needs such as those with dyslexia.

\subsection{Interviews' findings}

In the interviews, Algerian EFL teachers identified a serious absence of technology, where the following themes underline teachers' views on the actual situation and technology use:

\subsubsection{Lack of technology in teaching:}

Interviews showed that the overwhelming majority of participant EFL teachers in Algerian middle schools stated that there is a huge lack of employing technology when teaching English. Teachers also claimed that they have no familiarity with particular technology to teach those with dyslexia where even their information about reading difficulties is limited. In these concepts, Fatima claimed that:

"As an experienced teacher in middle school, I can confirm that the traditional way of teaching EFL is still followed with a complete absence of the technological devices' help in teaching and easily acquiring the language. I can ensure that textbooks are the major reference used for teaching English in the classroom which makes the education system not innovative... this causes problems even to those who suffer from particular issues such as difficulties in reading."

In the same way, Adham said that:

"I think that the use of technology is very effective and useful when teaching not only English. The new generation reforms start speaking about the use of technology but there is no real practice. Regarding teaching those with dyslexia, I cannot see any consideration to such type of pupils, where even our information about their type of learning is poor. Let me say that teaching English in Algeria is still very standard and classic where it time to bring new technology and adopt new principles that take into consideration all type of pupils"

\subsubsection{Reliance on traditional materials}

Not different from the previous theme, Algerian EFL teachers clearly explained the lack of modern resources that are nowadays very important in teaching. For example, Hibato-Allah and Chihane shared the same opinion, reporting that 
Fekih, M. (2018). The lack of technology in teaching EFL to learners with dyslexia in Algeria. International Journal of Social Sciences and Education Research, 4(4), 721-729.

In Algeria, the educational system is still relying on traditional methods and material when teaching English. There is an absence of sophisticated materials, sometimes when presenting new units with students projects we cannot find even a Data Projector. I believe that it is very important for the program's designers to integrate technology and think about the differences between learners and their needs

The situation of teaching in Algeria does not stop at the level of technology, Participants such as Houssame and Nourddine added to the point of poor technology when they underlined a very important area which is rural schools which until now are still struggling from poor educational conditions. In this matter, Houssame and Nourddine maintained that

" There is a total absence of technology at rural schools, to be honest with you, we are teaching through the use of completely traditional methods, we are still using chalk, blackboard where most of the time even textbooks are not available, which make two learners sharing that same book in one table".

Regarding the bad conditions, they added that "Learners in rural areas still struggling from transportation, ill-equipped classrooms, let alone thinking of technology".

\subsection{Focus group findings}

In addition to what teachers reported in the interviews, those who participated in the focus group also stressed the poor use of technology in Algeria.

\subsubsection{Lack of support to teachers}

This theme presents what EFL teachers declared about the lack of educational support to teachers in order to be qualified to use technology as well as being provided with appropriate devices that can be used to teach English to learners and specifically to those with dyslexia and other related disabilities. Some teachers such as Hanine, Rimas and Hatime claimed that

"It is also very important to support teachers in being qualified to use technological devices and train them in how to employ them appropriately to teach in an effective way where all learners can benefit."

In the same manner, Rabie claimed that

" To be honest with you, technology is not my cup of tea, simply because I do not know how to use it. I spent 23 years teaching English using the black-board and textbooks. I am encouraging the use of technology, however as my colleagues said we need support in adopting technical materials and most importantly how to use them"

That can help to highlight that lack of teachers' support and training in using technology exacerbates the problem of employing and or integrating technology even if it exists. The problems might be bigger and harder when teaching those with special needs especially when the teachers do not know what kind of appropriate technology can be used. Therefore, the lack of support and guidance might present an obstacle for teachers, and with less understanding of the appropriate use to the technology teachers might struggle, and students can be negatively affected by making less progress. And that, in turn, might be catastrophic for learners, especially those with dyslexia. 
Fekih, M. (2018). The lack of technology in teaching EFL to learners with dyslexia in Algeria. International Journal of Social Sciences and Education Research, 4(4), 721-729.

\section{Discussion}

According to Agudo (2014), the employment of technological equipment in education it is of paramount significance now. Based on the results, Algerian EFL teachers are aware of the importance of mastering educational technology in order to make learning English smooth and easy where learners' difficulties are taken into consideration. However, findings revealed that teachers are not familiar with modern technology as they find it complicated and not easy to be employed. This result supports Balckin and Wild's (2018) research in Malaysia where they also found that teachers struggle with the integrating of technology they have restricted capability and knowledge about it.

EFL teachers also have to be conscious of the learners' differentiated needs and exceptionalities and how technology facilitates learning English particularly to those with reading difficulties. However, findings gave a clear idea about teachers' insufficient knowledge regarding dyslexia and the proper technology that help affected learners. One of the reasons reported by teachers is lack of support which embodies again Balckin and Wild research results where teachers in Malaysia are struggling with lack of teachers' support. In addition to that, poor training was also stated by participants: unsatisfactory training is one of the reasons that negatively affect Algerian knowledge in the use of technology especially to accommodate students with dyslexia. This finding goes hand in hand with Iknouye and Clarke (2017) who also showed that teachers in Canada struggle with technology where a need for specific training was identified.

The present situation may make learners with dyslexia struggle even more with learning English. However, teachers recommended support and special training as they believe that technology can provide great help and in different ways, for to facilitate both teaching and learning processes, especially in meeting the need of those with specific education needs such as those who suffer from dyslexia. Numerous research studies highlighted the need of taking learners' interests into consideration Ertmer et al (2012). Other studies such as Nicolson et al (1999), Hatcher (2003), and Wolf (2001), revealed that technology can effectively help those with dyslexia improve their capacities and overcome their difficulties in different manners. Hence, with little efforts by providing teachers with professional development opportunities as well as giving them appropriate technical materials great changes might occur. Helpful educational technologies, especially with proper knowledge on how to use it, can enable all learners despite their varieties to produce visual, audio and kinetic performances. Because modern technological devices can afford real access to sounds, images, films, colors, and audio-text, concrete objects that they become visible to be ultimate types of equipment for the cognitively varied classroom where inclusive education can be achieved and realized.

\section{Conclusion}

In Algeria, and according to this study, EFL teachers are still using traditional methods in the classroom where the classroom teachers teach learners largely without taking into account their pupils learning exceptionalities, different needs, and interests. In addition to that, findings reveal that there is a serious lack of using technology in Algeria, where even teachers do not know how to use technical devices because of their limited capacities in mastering modern technology. Teachers' answers could also bring to light that there are a lot of educational issues which are presenting stumbling-blocks to teachers in order to use technology and making the learning process easier especially for those with dyslexia. Other issues such as teachers' lack of knowledge 
Fekih, M. (2018). The lack of technology in teaching EFL to learners with dyslexia in Algeria. International Journal of Social Sciences and Education Research, 4(4), 721-729.

of dyslexia and the proper way to meet affected learners needs are also preventing the employ of technology in the classroom. More to the point, there is a lack of supporting teachers with accurate training on how to use technology with consideration and understandings to learners needs. Teachers showed that they are realizing the importance of technology where they critically see that there is an urgent need to integrate technology to improve the educational system as well as the responsibility of the teacher in being qualified and aware. However, there are other serious obstacles such as teachers' and learners' adaptation to new technology, the cost of future reforms, besides policy guidelines, and the capacity of the programme and curriculum designers to being inclusive and open to facilitate learning English and improving the use of technology especially to teach those with dyslexia. The poor conditions in rural schools, reported here by participants, also highlights the significant challenge to Algeria in seeking to enhance inclusive education and provide teachers and learners with the resources required to meet their specific needs.

\section{References}

Anderson, P. L., \& Meier-Hedde, R. (2001). Early case reports of dyslexia in the United

States and Europe. Journal of Learning Disabilities, 34(1), 9-21.

Bain, A., \& Weston, M. E (2012). The learning edge: What technology can do to educate all children. New York: Teachers College Press.

Balchin, K., \& Wild, C. (2018). It's All in the Numbers: Enhancing Technology Use in Urban and Rural Environments. In: Cross-Cultural Perspectives on Technology-Enhanced Language Learning (pp. 203221). United State of America: IGI Global.

Beaton, A. (2004). Dyslexia, reading and the brain: A sourcebook of psychological and biological research. New York: Psychology press.

Bryman, A., \& Bell, E. (2015). Business research methods. ( $4^{\text {th }}$ ed.). New York. Oxford University Press, USA.

Bryman, A. (2006). Integrating quantitative and qualitative research: how is it done?. Qualitative research, 6(1), 97-113.

Coltheart, M. (2005). Modeling reading: The dual-route approach. The science of reading: A handbook, 623.

Creswell, J. W. (2014). A concise introduction to mixed methods research. London: Sage Publications.

Derntl, M., \& Calvo, R. A. (2010). Embedding Educational Design Pattern Frameworks into Learning Management Systems. In: Technology Enhanced Learning. Quality of Teaching and Educational Reform (pp. 439-445). Springer, Berlin, Heidelberg.

Ertmer, P. A., Ottenbreit-Leftwich, A. T., Sadik, O., Sendurur, E., \& Sendurur, P. (2012). Teacher beliefs and technology integration practices: A critical relationship. Computers \& Education, 59(2), 423-435.

Fletcher, J. M., Francis, D. J., Rourke, B. P., Shaywitz, S. E., \& Shaywitz, B. A. (1992). The validity of discrepancy-based definitions of reading disabilities. Journal of Learning Disabilities, 25(9), 555-561.

Gray, C., \& Kinnear, P. R. (2012). IBM SPSS statistics 19 made simple. New York: Psychology Press.

Hatcher, P. J. (2003). Reading intervention: A 'conventional'and successful approach to helping dyslexic children acquire literacy. Dyslexia, 9(3), 140-145.

Ikenouye, D., \& Clarke, V. B. (2017). An Integral Analysis of Teachers' Attitudes and Perspectives on the Integration of Technology in Teaching. In Technology Adoption and Social Issues: Concepts, Methodologies, Tools, and Applications (pp. 1246-1272). United State of America: IGI Global.

Johnson, R. B., Onwuegbuzie, A. J., \& Turner, L. A. (2007). Toward a definition of mixed methods research. Journal of mixed methods research, 1(2), 112-133. 
Fekih, M. (2018). The lack of technology in teaching EFL to learners with dyslexia in Algeria. International Journal of Social Sciences and Education Research, 4(4), 721-729.

Lerner, J.W. and Johns, B. (2011). Learning disabilities and related mild disabilities. (12 $2^{\text {th }}$ ed.). Wadsmorth: Cengage Learning.

Lyon, G.R., Shaywitz, S.E. \& Shaywitz, B.A. (2003). A definition of dyslexia. Annals of Dyslexia, 53(1), $1-14$.

Miles, T.R. and Miles, E. (1999). Dyslexia: A Hundred Years on. Open University Press.

Morgan, W.P. (1896) A case of congenital word blindness. British medical journal, 2 (1871), 1378.

Nagel, D. (2013, April 6). 6 Technology challenges facing education. THE Journal. Retrieved from https:/thejournal.com/articles/2013/06/04/6-technology-challenges-facing-education.aspx

Nicolson, R.I., Fawcett, A.J., Moss, H., Nicolson, M.K. and Reason, R. (1999). Early reading Orton, S.T. (1925). Word-blindness in school children. Archives of Neurology \& Psychiatry, 14 (5), 581-615.

Orb, A. (2007). Who gets what? In other words the allocation of resources. In: Hawley, G. (Eds.), Ethics in clinical practice: An interprofessional approach (pp. 300-318). Harlow: Pearson.

Ott, P. (1997). How to detect and manage dyslexia: A reference and resource manual. Oxford: Heinemann.

Reid, G. (2016). Dyslexia: A practitioner's handbook. (5 $5^{\text {th }}$ ed.). Maden: John Wiley \& Sons.

Schneider, E., Crombie, M. and Association, B.D. (2003). Dyslexia and Foreign Language Learning. New York: David Fulton.

Selikowitz, M. (2012). Dyslexia and Other Learning Difficulties. (5 $5^{\text {th }}$ ed.). OUP Oxford.

Stengel, E. (1952) Specific dyslexia ("congenital word-blindness"); a clinical and genetic study. The Eugenics Review, 44 (1), 46.

Thompson, S. and Vaughn, S. (2004). Research-Based Methods of Reading Instruction Grade K-3. ASCD: Beauregard St., Alexandria, USA.

Townend, J. and Turner, M. (2012). Dyslexia in Practice: A Guide for Teachers. New York: Springer US.

Vaughn, S., Chard, D.J., Bryant, D.P., Coleman, M., Tyler, B.-J., Linan-Thompson, S. and Kouzekanani, K. (2000). Fluency and Comprehension Interventions for Third-Grade Students. Remedial and Special Education, 21(6), 325-335.

Wang, V.C.X. (2014). Handbook of Research on Education and Technology in a Changing Society. United State of America: IGI Global.

Wolf, M. (Ed.) (2001). Dyslexia, fluency, and the brain. Timonium, MD: York Press. 